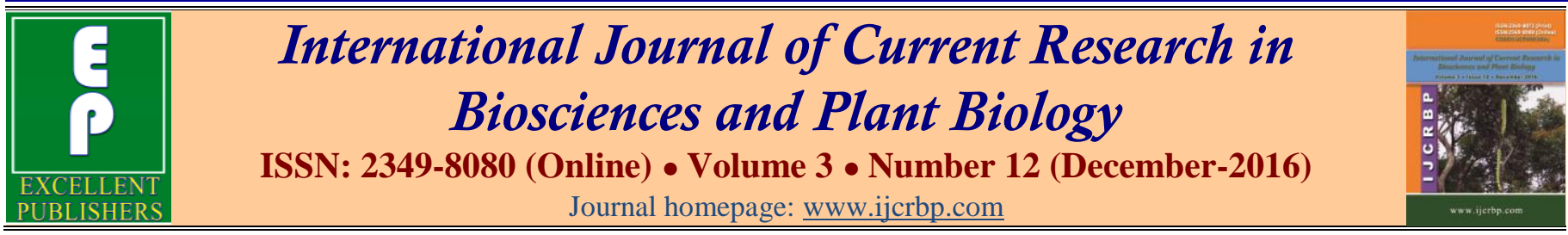

\title{
Mycorrhizal Effects on Growth and Root Morphology are Associated with Changes in Chlorophyll and Carbohydrates in Trifoliate Orange Seedlings
}

\author{
Ge-Ge Chi'1,2 and Qiang-Sheng $\mathrm{Wu}^{1,2,3}$ * \\ ${ }^{1}$ College of Horticulture and Gardening, Yangtze University, Jingzhou, Hubei 434025, China \\ 2 Institute of Root Biology, Yangtze University, Jingzhou, Hubei 434025, China \\ 3 Department of Chemistry, Faculty of Science, University of Hradec Kralove 50oo3, Hradec Kralove, Czech Republic
}

*Corresponding author.

\section{Abstract}

The effects of an arbuscular mycorrhizal fungus, Diversispora spurca, on plant growth, root morphology, chlorophyll concentration, and carbohydrate contents in trifoliate orange grown in a rootbox divided by $37-$ or $0.45-\mu \mathrm{m}$ mesh were studied. After 18 weeks of mycorrhizal inoculation, root colonization was higher under $37-\mu \mathrm{m}$ mesh than under $0.45-\mu \mathrm{m}$ mesh. Mycorrhizal inoculation significantly increased growth performance (plant height, stem diameter, leaf number, shoot and root biomass) and root morphology (the number of 1st-, 2nd-, and 3rd-order lateral roots, root length, projected area, surface area, volume, tips, forks, and crossings), and the effects were superior under $37-\mu \mathrm{m}$ than $0.45-\mu \mathrm{m}$. In addition, mycorrhizal colonization dramatically increased chlorophyll a, chlorophyll b, carotenoids, and total chlorophyll concentrations and also promoted sucrose and glucose contents in leaf, root, and total plant. These results indicate that mycorrhiza-promoted effects on growth and root morphology are potentially associated with changes in chlorophyll and carbohydrates.
\end{abstract}

\section{Article Info}

Accepted: 29 November 2016

Available Online: 06 December 2016

Keywords

Arbuscular mycorrhiza

Glucose

Hyphae

Root morphology

Sucrose

\section{Introduction}

Roots are a support system in plants, considering as the nutrient uptake organ (Elsen et al., 2003). Root morphology refers to the spatial distribution of the root system in soils, which could be affected by various factors, including soil moisture, soil bulk density, soil microorganisms, etc. Arbuscular mycorrhizal fungi (AMF) are a kind of beneficial microorganisms in the soil, which establish symbiotic associations with plant roots. Mycorrhizal symbiosis develops extraradical hyphae outside the root to contribute roles in nutrient and water absorption, plant growth, and substance communications. As mycorrhizas are established in roots, it is not clear whether the formation of mycorrhizal symbioses stimulates root morphology in the host plant.

Carbohydrates are one of the most important plant photosynthates, participating in the process of plant growth and metabolism. AMF help plants to absorb water and nutrients, and in return it needs to obtain carbohydrates, especially glucose, from host plants to mycorrhizas (Schubert et al., 2004). Studies in the past showed that AMF inoculation could improve the carbon metabolism of plants, such as the increase of plant carbohydrate concentrations and leaf photosynthesis 
(Jiang et al., 2008). As stated by Leake et al. (2004), AMs would consume 4-20\% of carbohydrates produced by photosynthesis of the host plant (Bago et al., 2003). As a result, mycorrhizal association can enhance a sink demand for carbohydrates from the host plant to the fungal partner (Zhu and Miller, 2003).

The objective of this study was to determine the effect of AMF colonization on growth performance, root morphology, carbohydrates, and chlorophyll concentrations in trifoliate orange grown in a twochambered rootbox.

\section{Materials and methods}

\section{Experimental apparatus}

The experimental apparatus was divided into upper and down parts. The upper part is characterized with $8 \mathrm{~cm}$ length of side and $11.3 \mathrm{~cm}$ height. In the location of the $4.3 \mathrm{~cm}$ tall, a 1-cm width organic glass was fixed in the periphery of cube. The $37-\mu \mathrm{m}$ and $0.45-\mu \mathrm{m}$ nylon mesh was covered at the bottom of the upper part. Hereinto, the mycorrhizal extraradical hyphae pass through $37-\mu \mathrm{m}$ mesh, but do not allow root entering, and the $0.45-\mu \mathrm{m}$ mesh can't allow the entering of roots and hyphae. The down part is characterized with $8.8 \mathrm{~cm}$ length of side and $6.5 \mathrm{~cm}$ height. The upper part was placed on the down part, resulting in the $4.3 \mathrm{~cm}$ overlapping region.

\section{Plant growth}

The four-leaf-old seedlings with uniform size (nucellar seedlings) and non-mycorrhization were transplanted into the upper part of the experimental apparatus, filled with autoclaved $\left(121^{\circ} \mathrm{C}, 0.11 \mathrm{Mpa}, 40 \mathrm{~min}\right) 4-\mathrm{mm}$ size air-dried soil. Approximate 1150 spores of Diversispora spurca were inoculated in the upper part. The non-AMF treatment also received the same quantity of the autoclaved inocula as the control. The soil (Xanthi-Udic Ferralsols, FAO system) was collected from the Citrus Orchard of the Yangtze University campus. The rootboxes were placed in a glass house from March 31 to August 4, 2014.

\section{Experimental design}

Four treatments with five replicates were arranged with a complete randomized design, for a total of 20 rootboxes. These treatments are as follows: (i) inoculation with $D$. spurca in the upper part of $37-\mu \mathrm{m}$ mesh $(\mathrm{AMF} / 37 \mu \mathrm{m})$, (ii) inoculation with $D$. spurca in the upper part of 0.45 $\mu \mathrm{m}$ mesh (AMF/0.45 $\mu \mathrm{m}$ ), (iii) inoculation without $D$. spurca in the upper part of $37-\mu \mathrm{m}$ mesh (non$\mathrm{AMF} / 37 \mu \mathrm{m}$ ), and (iv) inoculation without $D$. spurca in the upper part of $0.45-\mu \mathrm{m}$ mesh (non-AMF/0.45 $\mu \mathrm{m}$ ).

\section{Variable measurements}

Shoots and roots were respectively harvested on August 4, 2014, and their fresh biomass was determined. Plant height, stem diameter, and leaf numbers were measured before plant harvest. The root systems were washed with tap water to remove soil particles, placed in Regent's water-proof trays without root overlaps, and scanned by an Epson Perfection V700 Photo (Seiko Epson Corp, Nagano, Japan). The obtained images of roots were analyzed using the WinRHIZO 2007 (Regent Instruments Incorporated, Quebec, Canada) to determine projected area, surface area, average diameter, volume, tips, forks and crossings. The number of different order lateral roots was also manually counted.

Root AMF colonization was measured by the protocol of Phillips and Hayman (1970) in trypan blue staining. Determination of leaf chlorophyll was followed by Lichtenthaler (1987).

The concentration of sucrose, glucose, and fructose in leaves and roots was measured as per the protocol described by Zhang and Zai (2004).

\section{Statistical analysis}

Data were statistically analyzed using the SAS software (Version 8.1). Variance (ANOVA) was used to compare the significant difference with Duncan's Multiple Range tests at $p<0.05$.

\section{Results and discussion}

\section{Root mycorrhizal colonization}

Root mycorrhizal colonization was observed only in AMF-inoculated seedlings, but not in non-AMFinoculated seedlings, irrespective of $37-\mu \mathrm{m}$ and $0.45-\mu \mathrm{m}$ mesh. The seedlings had $39.3 \%$ of root mycorrhizal colonization under $\mathrm{AMF} / 37 \mu \mathrm{m}$ conditions and $32.2 \%$ under $\mathrm{AMF} / 0.45 \mu \mathrm{m}$ conditions, respectively. Meanwhile, root colonization was significantly higher under $\mathrm{AMF} / 37 \mu \mathrm{m}$ conditions than under $\mathrm{AMF} / 0.45 \mu \mathrm{m}$ conditions, suggesting that $37-\mu \mathrm{m}$ mesh benefits better mycorrhizal colonization in roots than $0.45-\mu \mathrm{m}$ mesh. 
Table 1: Effects of Diversispora spurca on plant growth performance of trifoliate orange grown in $37-\mu \mathrm{m}$ or $0.45-\mu \mathrm{m}$ mesh root-box.

\begin{tabular}{|c|c|c|c|c|c|}
\hline \multirow{2}{*}{ Treatments } & \multirow{2}{*}{ Plant height (cm) } & \multirow{2}{*}{ Stem diameter $(\mathbf{m m})$} & \multirow{2}{*}{$\begin{array}{l}\text { Leaf number } \\
\text { (per/plant) }\end{array}$} & \multicolumn{2}{|c|}{ Biomass in root+hyphae zone (g FW/plant) } \\
\hline & & & & Shoot & Root \\
\hline $\mathrm{AMF} / 0.45 \mu \mathrm{m}$ & $28.2 \pm 3.9 b$ & $2.85 \pm 0.19 b$ & $27.2 \pm 1.6 \mathrm{~b}$ & $2.13 \pm 0.22 b$ & $1.19 \pm 0.18 b$ \\
\hline $\mathrm{AMF} / 37 \mu \mathrm{m}$ & $42.5 \pm 2.8 \mathrm{a}$ & $3.40 \pm 0.16 \mathrm{a}$ & $32.0 \pm 2.7 \mathrm{a}$ & $3.92 \pm 0.62 \mathrm{a}$ & $1.72 \pm 0.24 \mathrm{a}$ \\
\hline Non-AMF/0.45 $\mu \mathrm{m}$ & $23.2 \pm 3.6 \mathrm{c}$ & $2.60 \pm 0.18 \mathrm{c}$ & $21.0 \pm 3.2 \mathrm{c}$ & $1.53 \pm 0.40 \mathrm{c}$ & $0.95 \pm 0.11 \mathrm{c}$ \\
\hline Non-AMF/37 $\mu \mathrm{m}$ & $22.3 \pm 2.5 \mathrm{c}$ & $2.54 \pm 0.19 \mathrm{c}$ & $23.0 \pm 3.7 \mathrm{c}$ & $1.40 \pm 0.10 \mathrm{c}$ & $0.88 \pm 0.06 \mathrm{c}$ \\
\hline
\end{tabular}

Note: Data (means $\pm \mathrm{SD}, n=5$ ) followed by different letters indicate significant differences (Duncan test, $p<0.05$ ) among treatments.

Table 2: Effects of Diversispora spurca on root morphology and number of lateral roots of trifoliate orange grown in $37-\mu \mathrm{m}$ or 0.45 - $\mu \mathrm{m}$ mesh root-box.

\begin{tabular}{|c|c|c|c|c|c|c|c|c|c|c|c|}
\hline \multirow[b]{2}{*}{ Treatments } & \multirow{2}{*}{$\begin{array}{l}\text { Length } \\
(\mathrm{cm})\end{array}$} & \multirow{2}{*}{$\begin{array}{l}\text { Projected } \\
\text { area }\left(\mathbf{c m}^{2}\right)\end{array}$} & \multirow{2}{*}{$\begin{array}{l}\text { Surface } \\
\operatorname{area}\left(\mathrm{cm}^{2}\right)\end{array}$} & \multirow{2}{*}{$\begin{array}{l}\text { Average } \\
\text { diameter } \\
(\mathrm{mm})\end{array}$} & \multirow{2}{*}{$\begin{array}{l}\text { Volume } \\
\left(\mathrm{cm}^{3}\right)\end{array}$} & \multirow[b]{2}{*}{ Tips } & \multirow[b]{2}{*}{ Forks } & \multirow[b]{2}{*}{ Crossings } & \multicolumn{3}{|c|}{ Number of lateral roots (\#/plant) } \\
\hline & & & & & & & & & $1^{\text {st }}$ & $2^{\text {nd }}$ & $3^{\text {rd }}$ \\
\hline $\mathrm{AMF} / 0.45 \mu \mathrm{m}$ & $341 \pm 29 b$ & $20.3 \pm 1.1 b$ & $63.6 \pm 3.4 b$ & $0.59 \pm 0.02 b$ & $0.95 \pm 0.04 b$ & $211 \pm 52 b$ & $1370 \pm 227 b$ & $250 \pm 50 b$ & $39 \pm 5 b$ & $166 \pm 18 b$ & $29 \pm 4 b$ \\
\hline $\mathrm{AMF} / 37 \mu \mathrm{m}$ & $530 \pm 134 a$ & $30.5 \pm 6.5 a$ & $95.7 \pm 20.4 \mathrm{a}$ & $0.58 \pm 0.03 b$ & $1.38 \pm 0.25 \mathrm{a}$ & $389 \pm 43 a$ & $2497 \pm 310 \mathrm{a}$ & $465 \pm 133 a$ & $53 \pm 3 a$ & $249 \pm 16 a$ & $37 \pm 5 a$ \\
\hline Non-AMF/0.45 $\mu \mathrm{m}$ & $199 \pm 77 c$ & $13.0 \pm 5.1 \mathrm{c}$ & $41.0 \pm 16.1 \mathrm{c}$ & $0.65 \pm 0.04 \mathrm{a}$ & $0.67 \pm 0.27 \mathrm{c}$ & $147 \pm 29 c$ & $574 \pm 358 c$ & $94 \pm 58 c$ & $30 \pm 3 c$ & $116 \pm 15 c$ & $23 \pm 4 c$ \\
\hline Non-AMF/37 $\mu \mathrm{m}$ & $204 \pm 31 c$ & $12.1 \pm 2.0 \mathrm{c}$ & $37.9 \pm 6.4 \mathrm{c}$ & $0.59 \pm 0.03 b$ & $0.56 \pm 0.11 \mathrm{c}$ & $115 \pm 17 \mathrm{c}$ & $651 \pm 129 c$ & $131 \pm 25 c$ & $32 \pm 7 \mathrm{c}$ & $102 \pm 16 c$ & $22 \pm 2 c$ \\
\hline
\end{tabular}

Note: Data (means $\pm \mathrm{SD}, n=5$ ) followed by different letters indicate significant differences (Duncan test, $p<0.05)$ among treatments.

G.-G. Chi and Q.-S. Wu (2016) / Mycorrhizal Effects on Growth and Root Morphology are Associated with Changes in Chlorophyll and Carbohydrates in Trifoliate 


\section{Plant growth performance}

Earlier studies had confirmed that inoculation of AMF induced the increase in plant growth (Wu et al., 2010). The present study also indicated that significantly higher plant height, stem diameter, leaf number, and shoot and root biomass ranked as the trend of $\mathrm{AMF} / 37 \mu \mathrm{m}>$ $\mathrm{AMF} / 0.45 \mu \mathrm{m}>$ non-AMF $/ 0.45 \mu \mathrm{m} \approx$ non-AMF $/ 37 \mu \mathrm{m}$ in the decreasing order (Table 1), suggesting that mycorrhizal inoculation heavily stimulated plant growth performance in trifoliate orange, regardless of $37-\mu \mathrm{m}$ and $0.45-\mu \mathrm{m}$ mesh. The mycorrhizal effect was superior under $37-\mu \mathrm{m}$ mesh than under $0.45-\mu \mathrm{m}$ mesh. We concluded that extraradical hyphae in the upper part could pass through the $37-\mu \mathrm{m}$ mesh, other than the 0.45 $\mu \mathrm{m}$ mesh, to the down part, resulting in extensive root absorptive areas.

\section{Root morphology}

Root projected area, surface area, volume, tips, forks and crossings were significantly increased by the inoculation with $D$. spurca, irrespective of $37-\mu \mathrm{m}$ and $0.45-\mu \mathrm{m}$ mesh (Table 2), which is in agreement with the findings by $\mathrm{Wu}$ et al. (2011) in trifoliate orange inoculated with Glomus mosseae and Glomus versiforme. Compared with $\mathrm{AMF} / 0.45 \mu \mathrm{m}, \mathrm{AMF} / 37 \mu \mathrm{m}$ treatment more highly increased all root morphology parameters, except for root average diameter (Table 2), suggesting that AMF has a positive effect. The improvement of root morphology under mycorrhization might lead to the promotion of plant growth performance. Our study also found that AMF inoculation significantly increased the number of first-, second-, and third-order lateral roots (Table 2), implying that AMF induced lateral root formation and development.

\section{Chlorophyll levels}

The present study showed that chlorophyll a, chlorophyll $\mathrm{b}$, carotenoids, and total chlorophyll concentrations were dramatically increased by mycorrhizal inoculation under both $37-\mu \mathrm{m}$ and $0.45-\mu \mathrm{m}$ mesh relative to nonmycorrhizal treatment (Fig. 1), which is consistent with the results of $\mathrm{Li}$ et al. (2013) on four citrus genotypes inoculated with $D$. spurca. Compared with the $\mathrm{AMF} / 0.45 \mu \mathrm{m}$ treatment, AMF inoculation under $37-\mu \mathrm{m}$ mesh conditions represented greater chlorophyll a, chlorophyll b, carotenoids, and total chlorophyll concentrations, which is consistent with the AM responses to plant growth performance and root morphology. Higher chlorophyll concentrations in AMF plant would help the host to enhance the photosynthesis, and thus more photosynthetic carbohydrates are produced for the utilization of AM sinks (Hajbagheri and Enteshari, 2011).

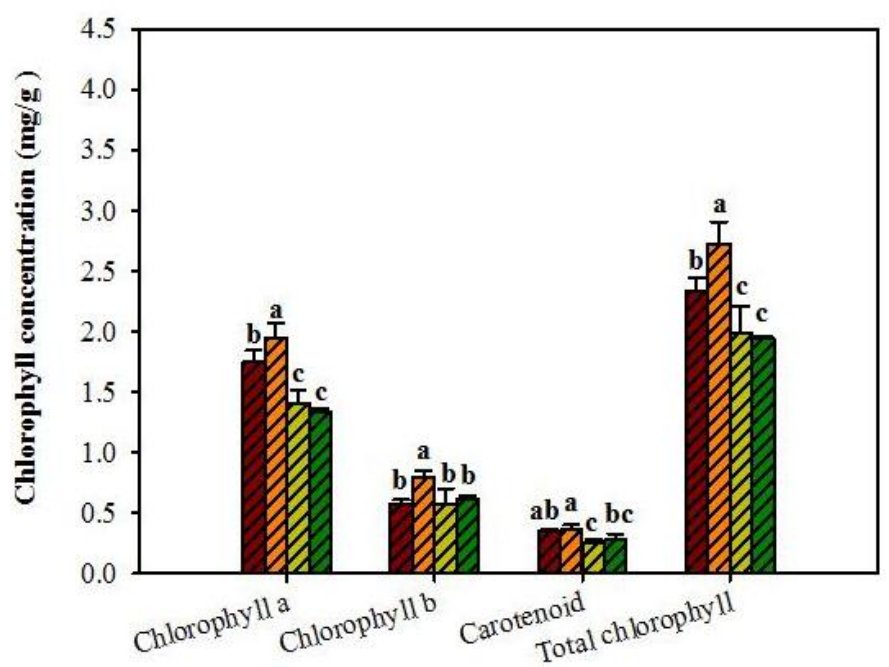

Fig. 1: Effects of Diversispora spurca on chlorophyll a, chlorophyll b, carotenoid and total chlorophyll concentrations in trifoliate orange grown in $37-\mu \mathrm{m}$ or $0.45-\mu \mathrm{m}$ mesh root-box. Date (mean $\pm \mathrm{SD}, n=5$ ) followed by different letters above the bars indicate significant differences (Duncan test, $p<0.05$ ) between the treatment.

\section{Carbohydrate concentrations}

In general, sucrose can be transferred into plant sinks and non-plant sinks, such as mycorrhizal sinks (Wu et al., 2013). Our results also showed that AMF significantly leaf glucose, fructose, and sucrose contents in trifoliate orange, irrespective of $37-\mu \mathrm{m}$ and $0.45-\mu \mathrm{m}$ mesh (Fig. 2a), which is a similar effect of AMF on chlorophyll levels. This indicated that AMF strongly stimulate the synthesis of chlorophyll and subsequently accelerate the production of photosynthates. On the other hand, AMF inoculation heavily increased glucose and sucrose contents while markedly decreased fructose contents in roots (Fig. 2b) and total plant (leaf + root) (Fig. 2c). Lerat et al. (2003) observed that root AMF colonization was generally linearly correlated with the C-sink strength of roots. The higher plant $\mathrm{C}$ assimilation rate would hence compensate for their greater below-ground $\mathrm{C}$ expenditure in AM symbioses (Eissenstat et al., 1993). In addition, root growth needs carbon sources as the metabolic substrate, and the increase in mycorrhizainduced glucose and sucrose contents would provide greater metabolic substrates for root development, which is a key factor in regulating root morphology (Koch et al., 2000). 


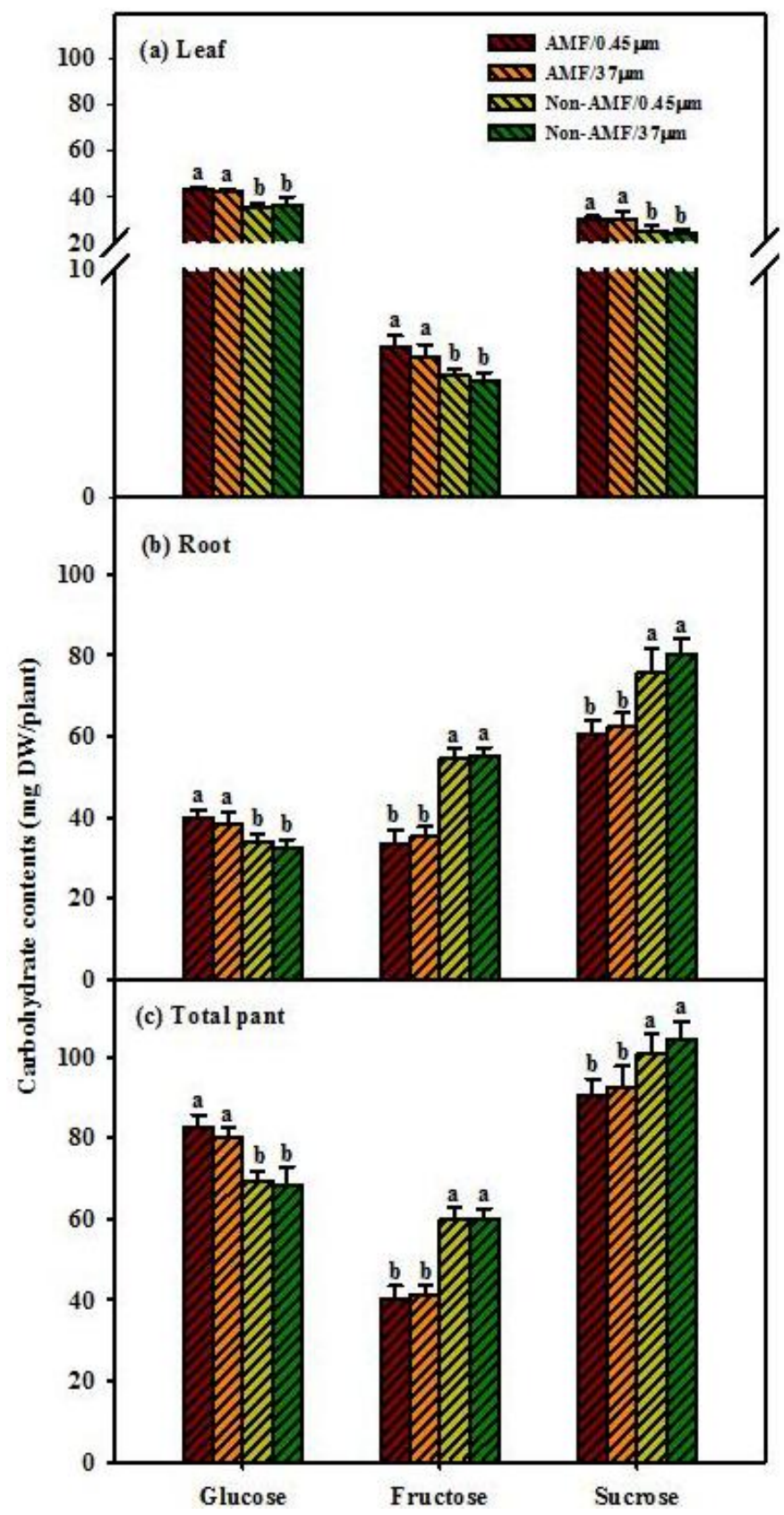

Fig. 2: Effects of Diversispora spurca on glucose, fructose, and sucrose concentrations in (a) leaf, (b) root, and (c) total plant (leaf + root) of trifoliate orange grown in 37- $\mu \mathrm{m}$ or 0.45 $\mu \mathrm{m}$ mesh root-box. Data (mean $\pm \mathrm{SD}, n=5$ ) followed by different letters above the bars indicate significant differences (Duncan test, $P<0.05$ ) between the treatments.

\section{Conclusion}

In our study, inoculation with D. spurca strongly improved plant growth performance and root morphology, which is potentially, associated with the increase in mycorrhiza-modulated chlorophyll and sucrose and glucose contents.

\section{Conflict of interest statement}

Authors declare that they have no conflict of interest.

\section{Acknowledgement}

This study was supported by the Plan in Scientific and Technological Innovation Team of Outstanding Young, Hubei Provincial Department of Education (T201604).

\section{References}

Bago, B., Pfeffer, P. E., Abubaker, J., Jun, J., Allen, J. W., Brouillette, J., Shachar-Hill, Y., 2003. Carbon export from arbuscular mycorrhizal roots involves the translocation of carbohydrate as well as lipid. Plant. Physiol. 131(3), 14961507.

Eissenstat, D. M., Graham, J. H., Syvertsen, J. P., Drouillard, D. L., 1993. Carbon economy of sour orange in relation to mycorrhizal colonization and phosphorus status. Ann. Bot. 71(1), 1-10.

Elsen, A., Beeterens, R., Swennen, R., De Waele, D., 2003. Effects of an arbuscular mycorrhizal fungus and two plant-parasitic nematodes on Musa genotypes differing in root morphology. Biol. Fertil. Soils. 38(6), 367-376.

Hajbagheri, S., Enteshari, S., 2011. Effects of mycorrhizal fungi on photosynthetic pigments, root mycorrhizal colonization and morphological characteristics of salt stressed Ocimum basilicum L. Iran. J. Plant. Physiol. 1(4), 215-222.

Jiang, G., Zhao, D., Zhang, G., 2008. Seismic evidence for a metastable olivine wedge in the subducting Pacific slab under Japan Sea. Earth. Plant Sci. Lett. 270(3), 300-307.

Koch, K. E., Ying, Z., Wu, Y., Avigne, W. T., 2000. Multiple paths of sugar-sensing and a sugar/oxygen overlap for genes of sucrose and ethanol metabolism. J. Exp. Bot. 51(Suppl. 1), 417-427.

Leake, J., Johnson, D., Donnelly, D., Muckle, G., Boddy, L., Read, D., 2004. Networks of power and influence: The role of mycorrhizal mycelium in controlling plant communities and agroecosystem functioning. Can. J. Bot. 82(8), 1016-1045.

Lerat, S., Lapointe, L., Piché, Y., Vierheilig, H., 2003. Variable carbon-sink strength of different Glomus mosseae strains colonizing barley roots. Can. J. Bot. 81(8), 886-889.

Lichtenthaler, K., 1987. Chlorophyll and carotinoids: pigments of photosynthetic brommembranes. Method. Enzymol. 148, 351-382.

Li, Y., Zou, Y. N., Wu, Q. S., 2013. Effects of Diversispora spurca inoculation on growth, root system architecture and chlorophyll contents of four citrus genotypes. Int. J. Agric. Biol. 15(2), 342-346.

Phillips, J. M., Hayman, D. S., 1970. Improved procedures for clearing roots and staining parasitic and vesiculararbuscular mycorrhizal fungi for rapid assessment of 
infection. Transac. Brit. Mycol. Soc. 55(1), 158-161.

Schubert, A., Allara, P., Morte, A., 2004. Cleavage of sucrose in roots of soybean (Glycine max) colonized by an arbuscular mycorrhizal fungus. New Phytol. 161(2), 495501.

Wu, Q. S., Zou, Y. N., He, X. H., Luo, P., 2011. Arbuscular mycorrhizal fungi can alter some root characters and physiological status in trifoliate orange (Poncirus trifoliata L. Raf.) seedlings. Plant Growth. Regul. 65(2), 273-278.

Wu, Q. S., Zou, Y. N., Huang, Y. M., Li, Y., He, X. H., 2013. Arbuscular mycorrhizal fungi induce sucrose cleavage for carbon supply of arbuscular mycorrhizas in citrus genotypes. Sci. Hortic. 160, 320-325.

Wu, Q. S., Zou, Y. N., Z, T. T., N, H. A., Liu, C. Y., 2010. Polyamines participate in mycorrhizal and root development of citrus (Citrus tangerine) seedlings. Not. Bot. Horti. Agrobot. Cluj. Napoca. 38(3), 25-31.

Zhang ZL, Zai L., 2004. Experimental Manual of Plant Physiology. $3^{\text {rd }}$ Edn. Higer Education Press, Beijing (in Chinese). pp. 127-130.

Zhu, Y. G., Miller, R. M., 2003. Carbon cycling by arbuscular mycorrhizal fungi in soil-plant systems. Trends Plant. Sci. 8(9), 407-409.

\section{How to cite this article:}

Chi, G.-G., Wu, Q.-S., 2016. Mycorrhizal effects on growth and root morphology are associated with changes in chlorophyll and carbohydrates in trifoliate orange seedlings. Int. J. Curr. Res. Biosci. Plant Biol. 3(12), 99-104. doi: http://dx.doi.org/10.20546/ijcrbp.2016.312.012 